\title{
The relationship between tactile thresholds and histology in the human finger
}

\author{
M F BRUCE AND D C SINCLAIR
}

Department of Anatomy, Aberdeen University.

SUMMARY Touch detection and two-point discrimination thresholds at three sites on the distal phalanx of the little finger were compared with the histology of the same three sites in amputated fingers. No consistent relationship could be demonstrated between sensitivity to touch and the population density of Meissner corpuscles or other organised endings. However, the findings do not negate the suggestion that Meissner corpuscles may be involved in two-point discrimination.

The corpuscles described by Wagner and Meissner ${ }^{1}$ have a characteristic morphology and distribution. Because they are present in considerable numbers in the ridged glabrous skin of primates, where touch sensitivity is great, they have long been regarded as tactile organs, and there have been various speculations regarding their precise function. At first it was generally believed that they conferred on the fingers a special tactile acuity, but in 1954 Cauna $^{2}$ suggested that Meissner corpuscles might play a part in the ability to discriminate two points, which is well developed in the finger pads. Talbot $e t a l^{3}$ produced evidence to link them with the sensation of 'flutter' (low frequency vibration), and in 1974 Mountcastle 4 stated his belief that they were detectors of movement. The presence in human skin of superficially situated, rapidly adapting mechanoreceptors ${ }^{56}$ has led to the suggestion that these are the Meissner corpuscles ${ }^{58}$ and Lindblom and Lindstrom ${ }^{\circ}$ have proposed that the rapidly adapting units are responsible for the detection of tactile stimuli because of their low threshold to indentation and low critical slopes. The Meissner corpuscles are therefore once again being invoked as threshold detectors.

All the evidence available is indirect, and it is worth recalling that in the past the Meissner corpuscle has also been thought of as a temperature sensing organ ${ }^{10}$ and even to be associated with pain. ${ }^{11}$ We therefore thought it worth while to explore two of the possible functions of the Meissner corpuscle by correlating passive tactile

Address for reprint requests: Mrs MF Bruce, Department of Anatomy, Marischal College, Aberdeen AB9 1AS.

Accepted 15 November 1979 and two-point thresholds on the human finger with the numbers of Meissner corpuscles in the same sites. The sites chosen were the palmar, lateral (radial) and dorsal aspects of the distal phalanx of the little finger of the non-dominant hand.

\section{Material and methods}

\section{HISTOLOGY}

Skin was obtained from traumatic amputations of the little finger from healthy adults (four males and one female) aged 16 to 25 years: all patients were engaged in manual work. Skin from the palmar and lateral surfaces was available from all five specimens, but dorsal skin was obtained from only three.

The skin was fixed in Bouin's fluid, embedded in paraffin wax, and cut normal to the surface, in serial sections at $15 \mu \mathrm{m}$. The sections were stained by the double impregnation silver technique of Fitzgerald. ${ }^{12}$ Each section was scanned for the presence of organised endings, and all the Meissner corpuscles in an area of 6 to $9 \mathrm{~mm}^{2}$ from each site were counted, their concentrations being expressed as corpuscles per $\mathrm{mm}^{2}$.

\section{THRESHOLDS}

All subjects were right-handed healthy medical students aged between 18 and 20 years; none had had any previous experience of sensory experiments.

Touch detection thresholds were determined in a quiet room by the method of limits, and at the outset the subjects were given a brief and standardised account of the procedure. They sat comfortably with the left forearm resting on a table 
and the hand cradled in modelling clay in such a way as to bring the appropriate test surface of the little finger horizontal. A screen prevented them from seeing the stimulus delivered, and care was taken to avoid auditory or visual cues which might signal the event.

On each site an area of approximately $1 \mathrm{~cm}^{2}$ was marked out, and stimuli were delivered at random within this area, the apparatus being moved slightly between each stimulation, so as to avoid hitting the same spot every time. The centre of the dorsal area was midway between the nail fold and the distal interphalangeal joint, that of the lateral area was at the level of the nail fold, and that of the palmar area was midway between the finger tip and the distal interphalangeal crease.

The apparatus used for stimulation is shown in fig 1. Ten graded nylon monofilaments were mounted on two interchangeable blocks of perspex, each of which could rapidly be fixed on the end of the carrier rod. The 'buckling loads' of these filaments had been determined by lowering them on to the pan of an analytical balance and recording the mean force at which the filament buckled. The lengths of the filaments were adjusted to give an approximately logarithmic series: - $0.015 \mathrm{~g}, 0.021 \mathrm{~g}, 0.053 \mathrm{~g}, 0.073 \mathrm{~g}$, $0.91 \mathrm{~g}, 0.253 \mathrm{~g}, 0.374 \mathrm{~g}, 0.650 \mathrm{~g}, 1.376 \mathrm{~g}$ and $2.62 \mathrm{~g}$.

A selected filament was lowered gently until its tip just touched the skin surface; it was then lowered by a further millimetre, upon which the filament buckled. Further descent was prevented by a check on the activating rod. The filament was then raised by three $\mathrm{mm}$ and allowed to fall freely, so delivering to the skin a force equal to its buckling load. The restriction of the excursion of the filament after hitting the skin virtually eliminated any "skidding" of its tip. The stimulus was allowed to remain in contact with the skin for one second and then raised again.

Subjects were instructed to say "yes" whenever they felt a filament touch the site; no equivocal responses were accepted. Stimuli were delivered at irregular intervals of three to five seconds in ascending order of magnitude; if with a given stimulus three stimuli were not detected, the next heavier stimulus was tried, and so on until 10 out of 10 "yes" responses were obtained. After 30 seconds' rest a descending series followed, and the threshold was taken as the mean of the buckling loads of the first ascending stimulus giving a score of eight out of 10 or more and the first descending stimulus giving a score of seven out of 10 or less. The subject was then allowed one to two minutes rest, during which he withdrew the hand from the clay and exercised it. After this the entire procedure was repeated for another stimulus site. The three sites were tested in random order, and the whole session was com-

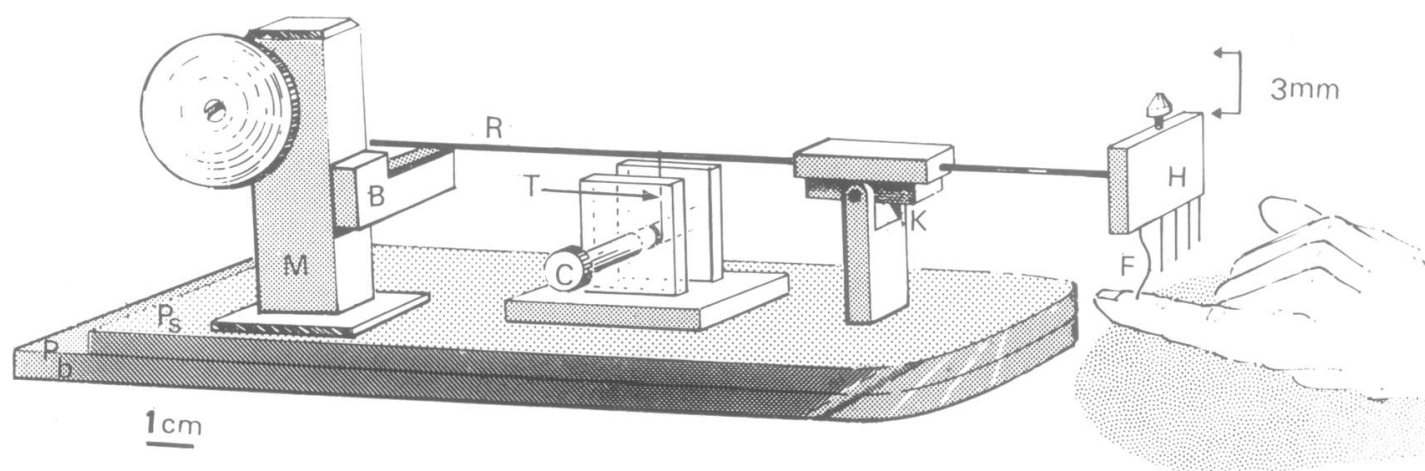

Fig 1 The rod $(R)$ carrying the stimulus head $(H)$ is pivoted on a knife edge $(K)$ standing on a perspex plate $\left(P^{*}\right)$ which can swivel on another similar plate $\left(P_{b}\right)$, so allowing the stimulator head to describe an arc of a circle. The middle of the rod is restrained by a thread $(T)$ wound round a friction-tight cylinder, $(C)$, rotating in perspex sockets. The thread is slackened off by rotating the cylinder until the appropriate nylon filament $(F)$ comes in contact with the skin, and a reading is taken from a vertically mounted mm scale (not shown). The thread is then paid out by another $\mathrm{mm}$, so that the filament buckles, and raised from this position through $3 \mathrm{~mm}$ by depressing the other end of the rod with the finger. The microscope rack and pinion assembly $(M)$ is then used to raise a horizontal bar $(B)$ covered with a thick layer of plastic foam to prevent noise, until it presses against the end of the rod held by the finger. The finger releases the rod at each stimulation, so allowing the stimulus to fall until the slack of the thread is taken up, that is by a distance of $3 \mathrm{~mm}$. The purpose of the bar is to check the distance travelled by the stimulus every time one is applied. 
pleted in about 30 minutes. Skin temperatures on the test site were recorded before each ascending series, in the interval following it, and at the end of the descending series.

Two-point discrimination thresholds were obtained by a similar technique. The subjects were instructed that they might feel one point or two; they were asked to report whether they felt one or two points when the stimulus was applied. Behind the screen a pair of sliding metal callipers with blunted points, bolted to the rack and pinion of a microscope stand, was lowered on to the skin of the test site. The tips were allowed to touch the skin, and lowered until the subject reported a firm contact. They were then raised by three $\mathrm{mm}$ and racked down again by this distance to produce the standard stimulus. Unknown to the subjects, all stimuli were of two points, the distance between them being gradually opened for the ascending series and closed for the descending one. Thresholds were assessed as outlined above, the ascending threshold being represented by a score of eight out of 10 or more and the descending threshold by one of seven out of 10 or less.

\section{Results}

\section{Histology}

The concentrations of Meissner corpuscles in the amputated material are shown in Table 1. There was no significant difference between the figures for the palmar and the lateral sites, but both were significantly greater than those for the dorsal site.

There were no obvious morphological differences between the corpuscles in lateral and palmar skin. Many of them were small and compact (fig 2), but larger, less well organised and more lobulated forms (fig 3) were quite often seen. The few corpuscles found on the dorsal surface were large, and often obliquely

Table 1 Mean numbers of Meissner corpuscles per $\mathrm{mm}^{2}$

\begin{tabular}{llll}
\hline Patient & Palmar & \multicolumn{2}{l}{ Site } \\
\cline { 3 - 4 } & & Lateral & Dorsal \\
\hline A & $27 \cdot 0$ & $17 \cdot 2$ & $7 \cdot 0$ \\
B & $20 \cdot 8$ & $15 \cdot 2$ & - \\
C & $24 \cdot 2$ & $20 \cdot 2$ & $1 \cdot 0$ \\
D & 16.8 & $21 \cdot 2$ & $1 \cdot 3$ \\
E & 14.6 & $13 \cdot 2$ & - \\
\hline Mean & 20.7 & $17 \cdot 4$ & $3 \cdot 1 *$ \\
\pm & \pm & \pm & \pm \\
S.E. & $2 \cdot 28$ & $1 \cdot 50$ & $2 \cdot 12$ \\
\hline
\end{tabular}

* Significantly smaller than either the palmar $(p<0.02)$ or the lateral $(p<0.05)$ figures. placed within a large dermal papilla which interrupted the otherwise relatively smooth junction between dermis and epidermis (figs 4,5 ).

Pacinian corpuscles were numerous in the ridged skin of the palmar and lateral sites, but none was seen in any of the samples of the thin dorsal skin. Merkel cell complexes were not obvious, though individual cells, tentatively identified as Merkel cells, were occasionally seen in all three skin sites (figs 5, 6). Ruffini type receptors were not seen in any specimen.

\section{Thresholds}

Some subjects manifested a "step" type of tactile threshold, an unbroken succession of failures to respond being followed by a sudden complete sequence of "yes" responses to the next heavier thread. Others showed a "ramp" approach, scoring a gradually increasing number of "yes" responses as the successively heavier stimuli were applied. This difference between subjects was not related to sex, the order of testing, or the site tested.

Five subjects on one or more occasions gave a "yes" response when no stimulus had been delivered. This always happened below the

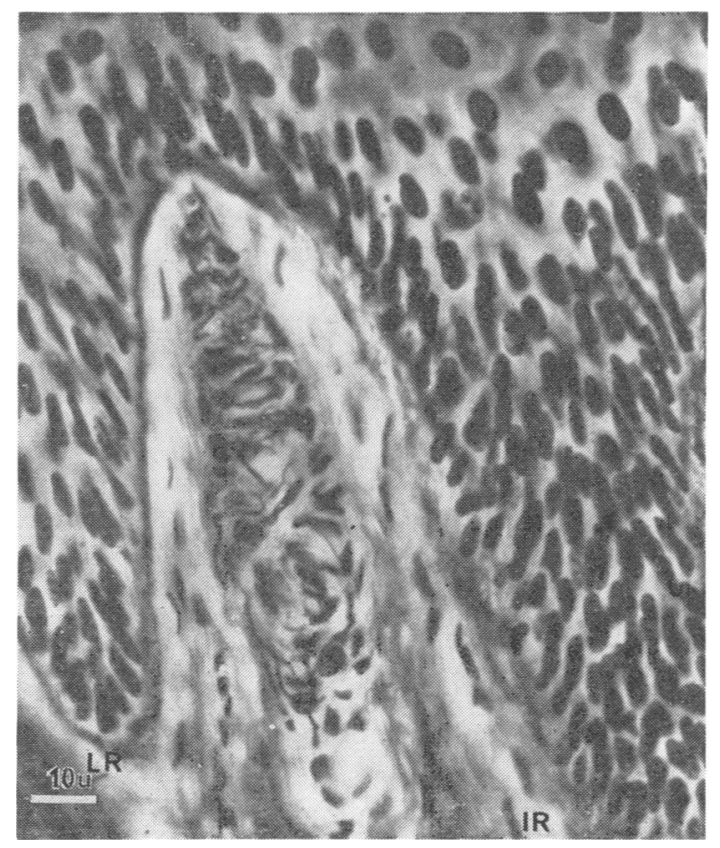

Fig 2 Compact Meissner corpuscle in a dermal papilla with a limiting ridge $(L R)$ on the left and an intermediate ridge (IR) on the right. Palmar surface, terminal phalanx, little finger; 18 year old male. 


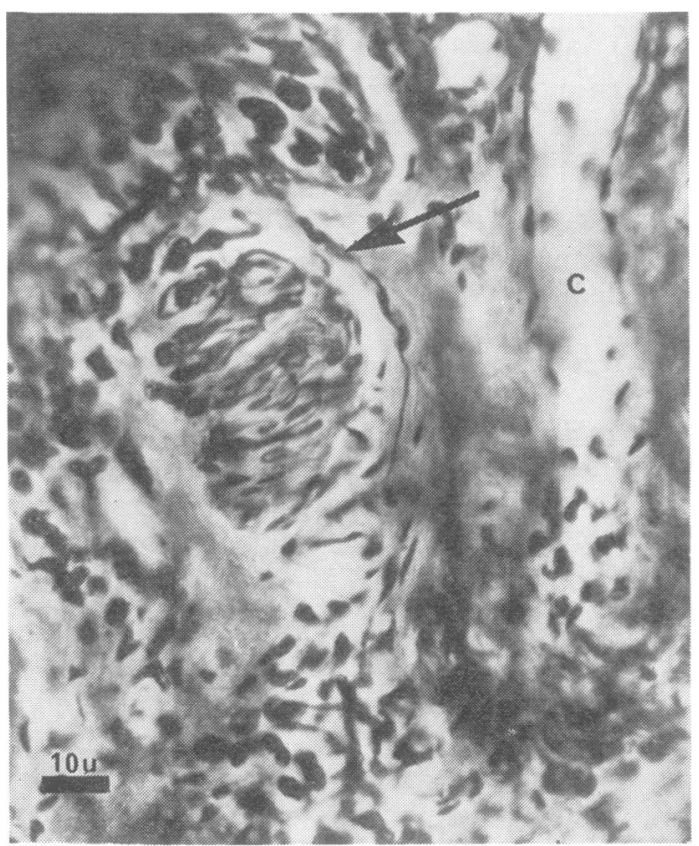

Fig 3 Less compact Meissner corpuscle. Note the nerve fibre (arrow) ascending alongside. A capillary $(C)$ is present in the same papilla. Palmar surface, terminal phalanx, little finger; same subject.

arbitrary threshold adopted, and only once did any subject record more than one such "false" response in any series of 10 stimuli.

Some subjects responded immediately the stimulus was applied, but others delayed, especially with stimuli below threshold. Some occasionally gave both an "on" and an "off" response-i.e. two "yes" responses to the one stimulus. The "off" responses occurred both below and above threshold, in both sexes and in all three sites.

Effect of skin temperature In spite of a range of skin temperatures from $21.3^{\circ} \mathrm{C}$ to $35.1{ }^{\circ} \mathrm{C}$ there was no correlation between site temperature and sensory threshold (fig 7).

Effect of sex A preliminary test on the lateral sites of 10 male and 10 female subjects gave a mean threshold of $0.08 \mathrm{~g} \pm 0.01$ for the females and $0.12 \mathrm{~g} \pm 0.03$ for the males, but the difference was not statistically significant $(\mathrm{p}>0.2)$.

Effect of site Table 2 shows the figures for the touch detection and two-point discrimination thresholds for all three sites. There were 11 subjects in the touch detection series (eight males and three females) and 10 different subjects (all males) in the two-point discrimination series. Examination of the figures showed that

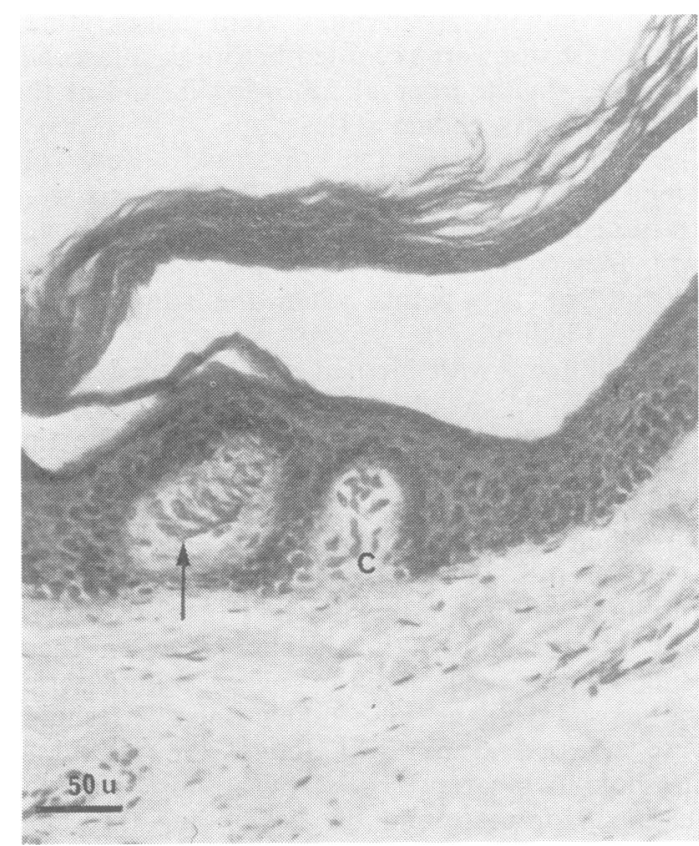

Fig 4 Meissner corpuscle (arrow) in a dermal papilla. $A$ capillary $(C)$ is present in the adjacent papilla. The remainder of the dermal-epidermal interface is smooth. Dorsal surface, terminal phalanx, little finger; same subject.

the mean touch threshold of $0.07 \mathrm{~g} \pm 0.006$ for the palmar site was significantly lower than either the lateral $(p<0.02)$ or the dorsal $(p<0.05)$ thresholds, but the difference between the lateral and dorsal sites, though in favour of the lateral site, was not statistically significant.

The mean thresholds for two-point dis-

Table 2 Summary of threshold results

\begin{tabular}{|c|c|c|c|}
\hline & \multicolumn{3}{|l|}{ Site } \\
\hline & Palmar & Lateral & Dorsal \\
\hline $\begin{array}{l}\text { Mean numbers of Meissner corpuscles } / \mathrm{mm}^{2} \\
\text { (from Table 1) }\end{array}$ & $\begin{array}{l}20.7 \\
\pm \\
2.28\end{array}$ & $\begin{array}{l}17 \cdot 4 \\
\pm \\
1.50\end{array}$ & $\begin{array}{l}3 \cdot 1 \\
t \\
2 \cdot 12\end{array}$ \\
\hline $\begin{array}{l}\text { Mean touch thresholds in } 11 \text { subjects } \\
\text { (grams) }\end{array}$ & $\begin{array}{l}0.07^{*} \\
\pm \\
0.006\end{array}$ & $\begin{array}{c}0.16 \\
\pm \\
0.03\end{array}$ & $\begin{array}{l}0 \cdot 19 \\
\pm \\
0 \cdot 06\end{array}$ \\
\hline $\begin{array}{l}\text { Mean two-point thresholds in } 10 \text { subjects } \\
(\mathrm{mm})\end{array}$ & $\begin{array}{l}2.90 \dagger \\
\pm \\
0.16\end{array}$ & $\begin{array}{c}3.40 \ddagger \\
\pm \\
0.20\end{array}$ & $\begin{array}{l}5.45 \\
\pm \\
0.86\end{array}$ \\
\hline
\end{tabular}

* Significantly lower than the lateral $(p<0.02)$ and dorsal $(p<0.05)$

figures.
+ Significantly smaller than the lateral $(p<0.05)$ and dorsal $(p<0.01)$ figures.

$\ddagger$ Significantly smaller than the dorsal $(p<0.05)$ figure. 


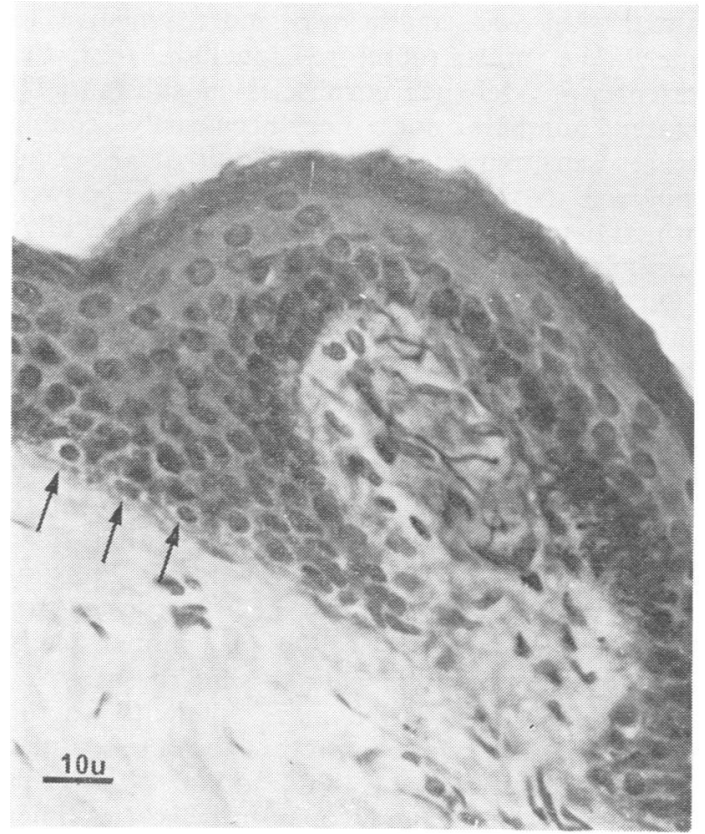

Fig 5 Meissner corpuscle with cells (arrows) tentatively identified as Merkel cells in the basal epidermal layer. This was the only specimen in which several of these cells were seen in a group. Dorsal surface, terminal phalanx, little finger; same subject.

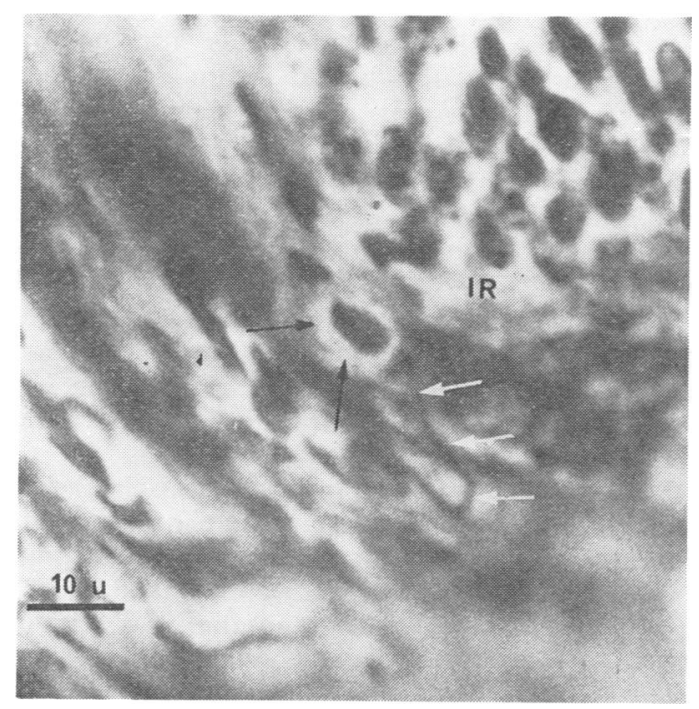

Fig 6 Cell (black arrows) identified as Merkel cell at the base of an intermediate ridge (IR). Note the nerve fibre (white arrows) in close proximity to the cell. Palmar surface, terminal phalanx, little finger; same subject.

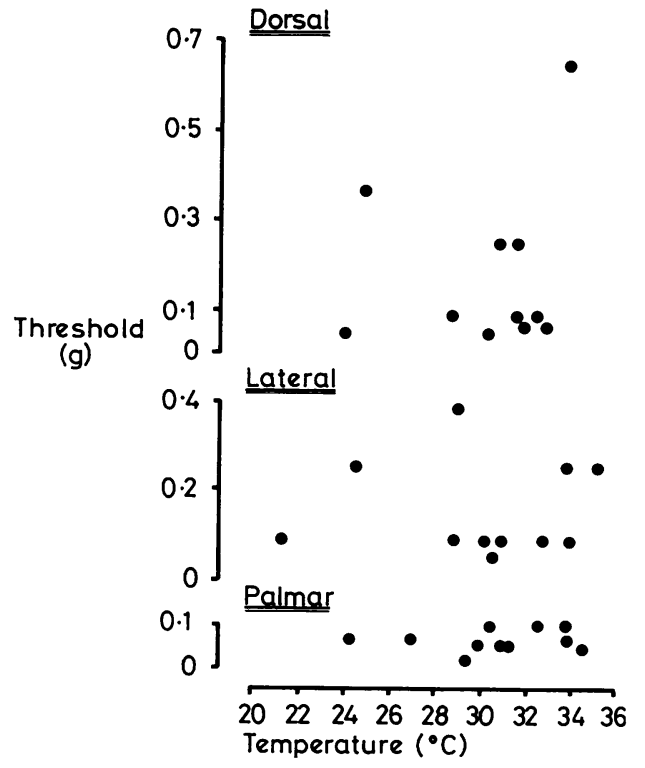

Fig 7 Effect of skin temperature on threshold.

crimination increased when followed from palmar to dorsal sites, the differences being statistically significant.

\section{Discussion}

Clinicians badly need a simple standardised method of establishing touch detection thresholds without having to use cumbersome research apparatus. The method used in this investigation has the essential simplicity of the von Frey hair without its major disadvantages of uncontrollable movement, variable application, and difficulty of accurate placement. It could perhaps form a basis for recording standard threshold data against which the performance of individuals could be evaluated; the instrument we used is cheap, portable, and easy to make.

The use of eight out of 10 positive responses as an arbitrarily defined threshold was suggested by Thompson et $a l^{13}$ on the following statistical grounds. With a stimulus intensity far below threshold the probability of obtaining a response is zero $(p=0)$. If the stimulus is far above threshold, $p=1$. If the stimulus is exactly at threshold level, chance alone would determine whether a given stimulus obtained a result or not, and $p=0 \cdot 5$, so that on applying the stimulus ten times, five positive responses would be expected. A finding of eight out of 10 positive responses exceeds the expected number by 1.9 
times its standard error, and such an excess would uccur by chance fewer than three times in a hundred. Hence it is legitimate to assume that the threshold has been passed. However open to mathematical argument this reasoning may be, the method has the advantage that if a subject accumulates three "misses" the experimenter can proceed to the next level of intensity without undue delay.

Sensory thresholds are influenced by many factors, both local and general ${ }^{14}$ and the number of Meissner corpuscles in the fingers varies with age $^{15}$ and the level of the site. ${ }^{16}$ In order to reduce these variables the test sites were on the same finger segment on the nondominant side of individuals of similar age and occupation, examined at one session under the same conditions. The sequence in which the test sites were stimulated was randomised so that any possible "learning effect" was obviated.

Two minor problems may be briefly mentioned. The finding that some subjects approached threshold in a step-like manner, while others approached it gradually, perhaps indicates that some aspect of personality may be involved in the decision-making process. Secondly, the occasional occurrence of both "on" and "off" responses to a single stimulus conflicts with the statement of Kenshalo ${ }^{17}$ that the force required to obtain an "off" response from a touch stimulus is six to 10 times as great as the force needed to elicit an "on" response. This was certainly not the case in the present investigation.

The most striking finding is the discrepancy between the touch detection thresholds and the populations of Meissner corpuscles. The figures for the density of corpuscles in the palmar aspect of the little finger are in good agreement with previous reports ${ }^{1518}$ and so the figures for the other two sites, obtained by the identical technique, may be regarded as giving a reliable comparative estimate of population densities. Although the histological material on which our counts are based was derived from manual workers, there appears to be no objection to comparing them with thresholds obtained from medical students, since Bolton et al ${ }^{19}$ found no evidence that occupation influenced the concentration of Meissner corpuscles. The dorsal skin had far fewer Meissner corpuscles per unit area than the lateral skin, yet the touch detection thresholds of the two areas did not differ significantly. Again, there was no significant difference between the populations of corpuscles in the palmar and the lateral sites, yet the palmar skin was significantly more sensitive to touch. We must therefore conclude that the presence of Meissner corpuscles in substantially greater numbers does not necessarily confer greater sensitivity to tactile stimuli of the kind employed. Nor do two areas similarly endowed with Meissner corpuscles necessarily have similar thresholds to such tactile stimuli.

Our results therefore fail to support the idea that Meissner corpuscles, whether or not they are to be identified with the rapidly adapting mechanoreceptors of electrophysiology, are responsible for the detection of tactile stimuli. It is, of course, possible that the Meissner corpuscles of the palmar surface have a more effective transduction mechanism, or that their performance is selectively modified by unmyelinated efferents, as has been suggested for the Pacinian corpuscle. ${ }^{20}$ A more likely supposition is that the palmar skin may convey the stimulus deformation more efficiently to the corpuscles. The ridge structure on the palmar and lateral surfaces of the terminal phalanx is similar, but the palmar epidermis is 1.6 times thicker. ${ }^{22}$ Or perhaps some as yet unidentified differences in the coupling of the receptors to the epidermis or connective tissue could influence stimulus transmission. As Quilliam ${ }^{21}$ has said, we need more information on the micromechanics of different skin areas.

Johnsson and Vallbo $^{6}$ found that, although the electrophysiological thresholds for rapidly adapting units in the human palm and finger tips were of the same order of magnitude, the psychophysical thresholds were lower in the finger tips. Vallbo ${ }^{8}$ accounted for this by postulating differences in the central processing of the information coming from the finger tips and from the palm. If this idea is correct, and there is no simple relationship between electrophysiological and psychophysical thresholds, we need not expect to find a simple correlation between endorgan concentrations and tactile thresholds.

If we reject the Meissner corpuscle as a threshold detector for touch what can we put in its place? Lindblom ${ }^{23}$ proposed the Pacinian corpuscle for this task, but later' (1976) withdrew the suggestion on finding that the rapidly adapting units were equally sensitive and had lower critical slopes. In our sections Pacinian corpuscles were equally abundant in lateral and palmar skin, but were never seen in dorsal skin.

Cauna $^{2}$ has suggested that the intermediate epidermal ridge, with its associated Merkel complexes, could form a receptor responding to 
the displacement of the overlying epidermal ridge. No quantitative estimates of the occurrence of these receptors seem, however, to have been reported. Chouchkov ${ }^{24}$ has never found Merkel complexes in the "adhesive ridges" of the human dermis, and Quilliam ${ }^{21}$ has stressed that the problem of their numbers and distribution in human glabrous skin remains unresolved.

Ruffini corpuscles were first described in human fingers ${ }^{25}$ but, although they are common in joint capsules ${ }^{26}$ and have been described in the hairy skin of cats $^{27}$ there do not appear to have been any recent reports of their presence in human glabrous skin. Nothing resembling a Ruffini corpuscle was seen in our sections.

We are therefore left with the free nerve terminals, and it may be that the differing sensitivity of the three areas is due primarily to differing densities of the populations of free terminals rather than those of the organised receptors, which may play a different role in sensation. The sensitivity of the dorsal surface could be assisted by the fact that the epidermis here is only about 0.6 times as thick as the lateral epidermis ${ }^{22}$ and the interface between dermis and epidermis is much smoother. Both factors might permit a deformation to be transmitted over a wider area, so recruiting more endings.

The two-point discrimination thresholds we obtained show a difference between palmar and lateral sites which one would not expect on the basis of the relative densities of Meissner corpuscles if these are to be accepted as the main endorgans concerned. But the trend of the figures is in the same direction as the figures for the Meissner distributions, and their possible role in two-point determination ${ }^{28} 29$ cannot be excluded. It is nevertheless necessary to remember that Meissner corpuscles are not needed for two-point discrimination elsewhere: the tip of the tongue and the tip of the nose perform better in distinguishing two points than the finger pads, ${ }^{30}{ }^{31}$ yet they contain no typical Meissner corpuscles. ${ }^{32}{ }^{33}$

In summary, the recorded differences in touch detection thresholds cannot be satisfactorily accounted for merely in terms of differential concentrations of organised receptors, though it remains possible that the Meissner corpuscle is concerned in two-point discrimination. It is perhaps important that our findings refer only to the passive reception of tactile stimuli, for it may be that the Meissner corpuscle has a role to play in what has become known as "active" touch ${ }^{34}$-that is discriminative activities in which handling of objects is involved. Cauna $^{35}$ suggested that direct recording from Meissner corpuscles might be feasible if the epidermis were shaved off. The exposed corpuscles could be identified by methylene blue and stimulated directly while recording from the appropriate cutaneous nerve. If this could be done, the situation would be appreciably clarified.

The technical assistance of $\mathrm{Mr}$ Alex Riddoch, Mr James Newlands and Mrs Alison Anderson is gratefully acknowledged, as is a grant to one of us (D.S.) from the Nuffield Foundation. We also thank the volunteers who took part, the Emergency and Accident Department of Aberdeen Royal Infirmary for their assistance in providing the amputation specimens, and the Department of Medical Illustration of Aberdeen University.

\section{References}

1 Wagner R, Meissner G. Über Vorhandsein bischer unbekannten eizenhumlichen Korperchen (Corpuscula Tacta). Nachrichten von der GeorgAugust-Universität und der Konigl Gesellschaft der Wissen-schaften $Z u$ Gottingen, 1852; 2:17-30.

2 Cauna $N$. The nature and functions of the papillary ridges of the digital skin. Anat Rec 1954; 119:449-68.

3 Talbot WH, Darian Smith I, Kornhuber HH, Mountcastle, VB. The sense of flutter-vibration: comparison of the human capacity with response patterns of mechanoreceptive afferents from the monkey hand. J Neurophysiol 1968; 31:301-34.

4 Mountcastle VB. In: Medical Physiology 13th ed, pp 285-347. St Louis: Mosby 1974: 285-347.

5 Knibestöl $M$. Stimulus response functions of rapidly adapting mechanoreceptors in the human glabrous skin area. J Physiol (Lond) 1973; 232: 427-52.

6 Johansson RS, Vallbo AB. Skin mechanoreceptors in the human hand: an inference of some population properties. In: Zotterman Y, ed Sensory Functions of the Skin in Primates. Oxford: Pergamon 1976: 171-84.

7 Iggo $\mathrm{A}$. Is the physiology of cutaneous receptors determined by morphology? In: Iggo A, Ilyinsky $\mathrm{OB}$, eds. Somatosensory and visceral receptor mechanisms. Progress in Brain Research, vol 43. Amsterdam: Elsevier, 1976; 15-31.

8 Valbo AB. Discussion. In: Zotterman Y, ed. Sensory Functions of the Skin in Primates. Oxford: Pergamon, 1976; 196.

9 Lindblom U, Lindstrom B. Tactile thresholds of normal and blind subjects on stimulation of 
finger pads with short mechanical pulses of variable amplitude. In: Zotterman Y, ed. Sensory Functions of the Skin in Primates. Oxford: Pergamon, 1976; 102-5.

10 Bourguignon G. Interpretation des sensibilités thermique et douloureuse à l'aide des chronaxies sensitives cutanées normale et de leur variation dans la syringomyélie. $R$ Acad Sci (Paris) 1933; 197:792-4.

11 Waterston D. Observations on Sensation. J Physiol (Lond) 1933; 77:251-7.

12 Fitzgerald MJT. Double impregnation silver technique for nerve fibres in paraffin sections. Q J Microscop Sci 1964; 105:359-61.

13 Thompson IM, Banks GF, Barron A, Fratis AM, Mattison BF. Differential elevation of cutaneous sensory thresholds by alternating currents applied to a nerve. $U$ Cal Pub Anat 1934; 1:167-94.

14 Sinclair DC. Psychophysiology of cutaneous sensation. In: Jarrett A ed The Physiology and Psychophysiology of the Skin. London and New York: 1973; 429-73.

15 Perez RM. Contribution à l'étude des terminaisons nerveuses dans la peau de la main. Trav lab de recherch biolog de l'Université de Madrid 1931; 27:187-226.

16 Meissner G. Beitrage zur Anatomie und Physiologie der Haut. Leipzig: Leopold Voss 1953.

17 Kenshalo DB. Biophysics and Psychophysics of Feeling. In: Carterette EC, Friedman MP, eds. Feeling and Hurting. Handbook of Perception, vol 6b. New York: Academic Press, 1978; 29-74.

18 Ronge H. Alterveranderungen der Meissnerchen Korperchen in der Fingerhaut. Zeitschrift für Mikroscopisch-Anatomische Forschung 1943; 54:164-7.

19 Bolton CF, Winkelmann RK, Dyck PJ. A quantitative study of Meissner's corpuscles in man. Neurology (Minneap) 1966; 16:1-9.

20 Santini M. A theory of sympathetic-sensory coupling. In: Zotterman Y, ed. Sensory Functions of the Skin in Primates. Oxford: Pergamon, $1976 ; 15-35$.

21 Quilliam TA. The structure of fingerprint skin. In: Gordon $G$ ed Active Touch. Oxford: Pergamon 1978; 1-18.

22 Whitton JT, Everall JD. The thickness of the epidermis. Br J Dermatol 1973; 89:467-76.
33 Lindblom U. Touch perception thresholds in human glabrous skin in terms of displacement amplitude on stimulation with single mechanical pulses. Brain Res 1974; 82:205-10.

24 Chouchkov C. Ultrastructure and morphological classification. In: Cutaneous Receptors. Advances in Anatomy, Embryology and Cell Biology vol 54. Berlin, Heidelberg, New York: Springer, 1978; 9-32.

25 Ruffini A. Sur un nouvel organe nerveux terminal et sur la presence des corpuscles GolgiMazzoni dans le conjonctif sous-cutane de la pulpe des doigts de l'homme. Arch Ital Biol 1894; 21: 249-65.

26 Halata $\mathrm{Z}$. The ultrastructure of the sensory nerve endings in the articular capsule of the knee joint of the domestic cat (Ruffini corpuscles and Pacinian corpuscles. J Anat 1977; 124:717-29.

27 Chambers MR, Andres KH, von During $M$ and Iggo A. Structure and function of the slowly adapting type II mechanoreceptors in hairy skin. J Exp Physiol 1972; 57:417-45.

28 Jabaley ME, Burns JE, Orcutt BS, Bryant WM. Comparison of histologic and functional recovery after peripheral nerve repair. $J$ Hand Surgery 1976; 1:119-30.

29 Gellis $\mathbf{M}$, Pool $\mathbf{R}$. Two point discrimination distances in the normal hand and forearm. $J$ Plast Reconstruct Surg 1977; 59:57-63.

30 Ringel RL, Ewanowski SJ. Oral perception: Two point discrimination. J Speech Hear Res 1965; 8:389-95.

31 Weinstein S. Effects of local anaesthetics on tactile sensitivity thresholds for cutaneous and mucous membranes, J Invest Dermatol 1977; 69:136-45.

32 Winkelmann RK. In: Nerve Endings in normal and pathologic Skin. Springfield: CC Thomas $1960 ; 58-66$.

33 Marlow CD, Winkelmann RK, Gibilisco JA. General sensory innervation of the tongue. Anat Rec 1965; 152:503-12.

34 Gordon G. In: Gordon G, ed Act:ve Touch. Oxford: Pergamon, 1978; 13-21.

35 Cauna N. Discussion. In: Somatosensory and visceral receptor Mechanisms. Progress in Brain Research, vol 43. Iggo A, Ilyinsky OB, eds. Amsterdam: Elsevier, 1976; 236. 